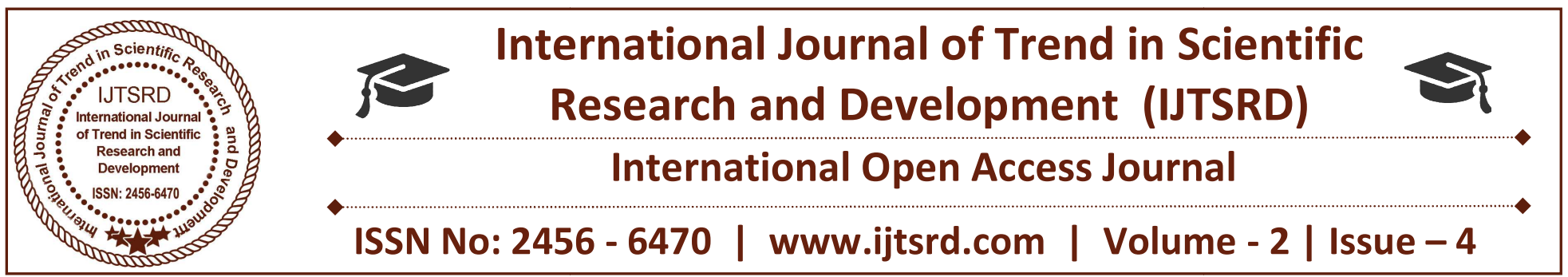

\title{
Arsenic Contamination of Ground water and Health Risk
}

\author{
Sanjay Kumar Verma, Dr. Ajay Kr. Upadhyay \\ P.G Department of Environmental Science, Magadh University Bodh Gaya, India
}

\section{ABSTRACT}

The arsenic poisoning due to contaminated groundwater in West Bengal, India, and all of Bangladesh has been thought to be limited to the Ganges Delta despite early survey reports of arsenic contamination in groundwater in the Union Territory of Chandigarh and its surroundings in the northwestern Upper Ganga Plain and recent findings in the Terai area of Nepal. Groundwater arsenic contamination and sufferings of people have been reported in 20 countries in different parts of the world. The magnitude is considered highest in five Asian countries and the severity is in order of Bangladesh $>$ India $>$ Mangolia $>$ China $>$ Taiwan. In all these countries, more and more groundwater withdrawal is taking place because of increase in agricultural irrigation. In India Maximum arsenic content was observed in bhojpur (bihar),. The groundwater of Bihar states is affected with arsenic contamination. A long-term environmental planning is essential to blunt the danger from such pollution. Analyses of the arsenic content of 206 tube wells showed that $56.8 \%$ exceeded arsenic concentrations of 55 micro $\mathrm{g} / \mathrm{L}$, with $19.9 \%>300$ micro $\mathrm{g} / \mathrm{L}$, the concentration predicting overt arsenical skin lesions. On medical examination of a self-selected sample of 150 person, $13 \%$ of the adults and $6.3 \%$ of the children had typical skin lesions, an unusually high involvement for children, except in extreme exposures combined with malnutrition. The urine, hair, and nail concentrations of arsenic correlated significantly with drinking water arsenic concentrations up to 1,648 micro g/L. On neurologic examination, arsenic-typical neuropathy was diagnosed in $65 \%$ of the adults, a prevalence previously seen only in severe, subacute exposures. We also observed an apparent increase in fetal loss and premature delivery in the women with the highest concentrations of arsenic in their drinking water. The possibility of contaminated groundwater at other sites in the Middle and Upper Ganga Plain merits investigation. Arsenic poisoning culminates into potentially fatal diseases like skin and internal cancers. This paper reviews sources, speciation, and mobility of Arsenic and global overview of groundwater contamination. The critically reviews the Arsenic led human health risks, its uptake, metabolism, and toxicity mechanisms. Our research provides an overview of the state-of-the-art knowledge on the alternative Arsenic free drinking water and various technologies (oxidation, coagulation flocculation, adsorption, and microbial) for mitigation of the problem of As contamination of groundwater.

Keywords: Ground Water, Surface Water, PhysicoChemical Parameters, Arsenic, Health, Ganga, toxic

\section{INTRODUCTION}

Ground water is the basic resource of drinking water. The ground water is potable when compared to surface water. The ground water is susceptible to pollution due to excessive usage of fertilizers, pesticides, increased anthropogenic activities and fast growth of industries. Thus, ground water is ultimate and most suitable fresh water resource with nearly balanced concentration of the salts for human consumption. Unfortunately, water resources are getting polluted and getting unfit for usage. Pollution of ground water aquifers has made many of the wells unfit for consumption. The availability of pure water through surface and ground water resources has become more critical day today. Only $1 \%$ is available on earth for drinking purpose, agricultural purpose, 
domestic purpose, power generation, industrial consumption, transportation and waste disposal.

Contamination of groundwater, either from anthropogenic or natural sources with several social impacts, has now turned to be a major environmental concern in different parts of the world. Millions of people in several countries are exposed to high levels of Arsenic via intake of Arsenic-rich groundwater. Elevated level of Arsenic in groundwater has been well documented in Chile, Mexico, China, Argentina, USA, and Hungary as well as in the Indian State of West Bengal, Bangladesh, and Vietnam. About 150 million people around the world are estimated to be affected globally with an increasing prospect as new affected areas are continuously discovered. Arsenic, a well-known carcinogen, is considered as one of the world's most hazardous chemicals. Excessive and long-term (such as 5-10 years) human intake of toxic inorganic As from drinking water and food may result in arsenicosis, a common name generally used for As related health problems including skin disorders, skin cancers, internal cancers (bladder, kidney, and lung), diseases of the blood vessels of the legs and feet, possibly diabetes, increased blood pressure, and reproductive disorders.

There are several states in India where more than $90 \%$ of the total populations are dependent on ground water for drinking and other purposes. The present study was taken under investigation to Analyze the impact of ground water quality of certain open wells and bore well water samples in selected locations in Bhojpur district of Bihar.

In terrestrial environment, the inorganic forms of Arsenic (such as trivalent arsenite and pentavalent arsenate are more prevalent and toxic than the organic forms in general. As exerts detrimental effects on general protein metabolism with high toxicity by reacting with sulfhydryl groups existing in cysteine residues.

Arsenicosis causes dire consequences for the livelihood, family life, and earning capability when individuals fall victim. Deterioration in physical appearance makes women socially excluded. At larger perspectives elevated As contamination of a region may result in societal stress, disability in individuals, poverty, and decreased market value of potentially contaminated agricultural products leading to low income to the affected farmers . Absence of taste, odour, colour, and exposure make As impossible for a layman to detect and avoid. Applying the WHO provisional guideline for drinking water of $10-50 \mathrm{ppb}$ of As, a population of more than 100 million people worldwide is at risk, and of these more than 45 million people mainly in developing countries from Asia are at risk of being exposed to more than $50 \mathrm{ppb}$ of As, which is the maximum concentration limit in drinking water in most of the countries in Asia.

At present, As is estimated to affect more than 150 million people worldwide with its increasingly elevated concentrations in drinking water. The major arsenicosis affected areas have been reported in large deltas and/or along major river basins across the world. The transfer of As to the food chain will ultimately remain as long-term risks to human and ecological systems. Since water is the principal route through which As enters into the human body, the understanding of the processes of As contamination in groundwater, associated health risks, and mitigation of As problem is required.

The present review summarizes possible sources of As contamination of groundwater, global overview of groundwater As contamination, toxicity, basic chemistry, associated health risks, and the best available strategies for mitigation of As pollution in groundwater.

\section{SOURCES, SPECIATION IN GROUND WATER}

Several natural and anthropogenic sources are deemed responsible for As contamination in groundwater. As occurs as a major constituent in more than 200 minerals and the desorption and dissolution of naturally occurring As bearing minerals and alluvial sediments result in high As concentration in groundwater in deltas and alluvial plains even if the As concentration in the solid phase is not high. The presence of metalloid in excess concentration in groundwater may be associated with ore deposits where As is present predominantly in sulfidic minerals such as arsenopyrite and pyrite. Arsenopyrite (FeAsS) is the most abundant As containing mineral generally existing in anaerobic environments and in various other rock forming minerals like sulfide, oxide, phosphate, carbonate, and silicate. It is present as a substitute of $\mathrm{S}$ in the crystal lattice of various sulfide minerals. Realgar (As4S4) and orpiment (As2S3) represent the two common reduced forms of As while in arsenolite (As2O3), As is present in oxidized form. Depending on the nature and texture of minerals, As can also be found in sediments, in the 
concentration range from 3 to $10 \mathrm{mg}$. The areas with high concentrations of $\mathrm{Fe}$ oxide or hydrous metal oxide or pyrites contain very high levels of As in sediments in comparison to other oxides. In reducing sediments, the concentration of As is found to be high; the concentration of As increases gradually with increase in the depth of the sediment. Fe and $\mathrm{Al}$ oxides present in sediments play a significant role for the contamination of groundwater. Reductive dissolution of $\mathrm{Fe}$ and $\mathrm{Al}$ metal oxides along with the activity of indigenous metal reducing bacteria is now deemed as the prominent release mechanism of As, directly effecting the mobility of As. The main anthropogenic sources for contamination of groundwater with As are mining, burning of fossil fuels, use of arsenical fungicides, herbicides and insecticides in agriculture, and wood preservatives. Burning of coal has profound effect on contamination of As in the environment. Emission of As takes place in the environment by volatilization of As4O6 due to burning of coal, which condenses in the flue system and ultimately transferred into water reservoirs. The degree of groundwater arsenic contamination by aforesaid anthropogenic sources is much less as compared to the natural sources; however, their contribution cannot be neglected.

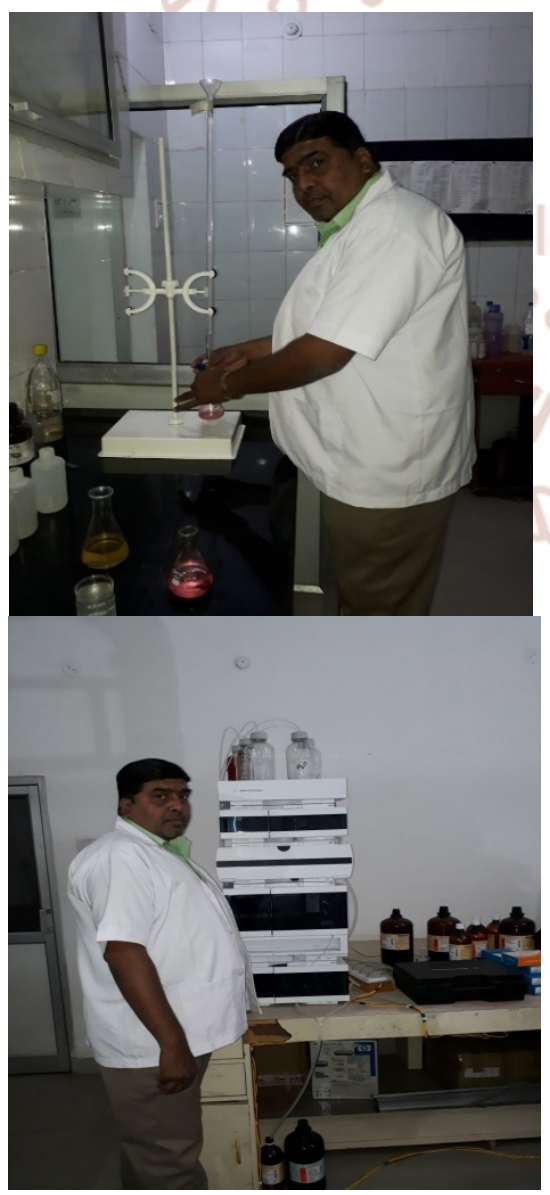

\section{Lab work}

Arsenic in groundwater exists primarily as oxy anions representing two oxidation states: arsenic (arsenite) and arsenic $(+\mathrm{V})$ (arsenate). Arsenic in groundwater exists primarily as oxy anions representing two oxidation states: arsenic (arsenite) and arsenic (arsenate). Both and exist within the $\mathrm{pH}$ range of 69. The predominant species are uncharged $\mathrm{H} 3 \mathrm{AsO} 3$ while the primary arsenate species are monovalent $\mathrm{H} 2 \mathrm{AsO}^{-4}$ and divalent . Geology and groundwater environment make one form, either or dominant. Although is thermodynamically favored in oxic waters and in anoxic waters, they have been also reported to coexist in both types of waters. Many researches of localized studies have reported the value of arsenic speciation information in explaining and understanding the behavior and characteristics of arsenic in the environment (solubility, mobility, etc.). The toxicity and the removability of arsenic differ between and is considered to be more toxic and more difficult to remove from water than. The variability of the arsenic concentration in groundwater is ascribed to the arsenic content of the aquifer and the varying dissolution/desorption processes releasing the arsenic from the solid phase into the liquid phase. Reductive dissolution of $\mathrm{Fe}$ oxides is considered as the principal cause of release from aquifer sediments.

\section{GROUND WATER CONTAMINATION}

ARSENIC

The contamination of Arsenic can be propagated defectively into the groundwater system because in groundwater and aquifers is mobilized (e.g., hydraulic fracturing). Hence, its contamination can affect a large population of people. Groundwater concentration of As has been documented in the literature which reveals a very large range from less than 0.5 to $5000 \mathrm{ppb}$ covering natural As contamination found in more than 70 countries. Some of the best WHO reported and most severe cases of arsenic contaminated groundwater have been found in aquifers across the globe. It represents that provisional guideline values for concentration in groundwater are commonly set at $10 \mathrm{ppb}$, although it can reach up to $50 \mathrm{ppb}$. The outcomes of this comparison affirm that contamination is a widespread global phenomenon and severe enough exceeding such guideline values. In fact, people consuming As-rich water for prolonged periods are reported to suffer from serious health problems in many parts of the world. 


\section{HEALTH RISK}

Arsenic contamination in the environment is turning to be a serious public health problem in several parts of the world. It is well-established fact that arsenite is more toxic than arsenate, with inorganic As being more toxic than organic. However, different organic species represent different degrees of toxicity. For instance, monomethylarsonicacid and dimethylarsinic acid, final As metabolites are less toxic than inorganic arsenic, whereas the degrees of toxicity of intermediate metabolites such as monomethylarsonous acid and dimethylarsinous acid are much more higher than inorganic arsenic. The toxicity of various arsenic species increases.

In terrestrial environment, mainly present inorganic which exists as pentavalent under aerobic condition and trivalent under anaerobic environment is generally found as a neutral species $(, \mathrm{pKa}=9.2)$ in aqueous solution at physiological $\mathrm{pH}$.cause toxicity differently Due to its structural similarity to glycerol, can be transported into cells through aqua glycerolporins, a pore protein for transporting small organic compounds such as glycerol and urea. However, takes different pathway into animals and human cells. As a phosphate an along, they have similar dissociation constants ( $\mathrm{pKa}$ of arsenic acid: 2.24, 6.69, and 10.3 and $\mathrm{pKa}$ of phosphoric acid: 2.26, 7.11, and 12.5). Similar to phosphate is found in water as an oxy anions in solution, that is, and at $\mathrm{pH} \mathrm{5-7.}$ As chemical analogs, they compete for their entry via phosphate transporters. Having entered into the human and animal cells, is rapidly reduced to. Thereafter, undergoes multisteps in cells through arsenitemethyltransferase (AS3MT) using Sadenosylmethionine (SAM) as the methyl donor, resulting in the formation of methylated first proposed the classical pathway of As methylation. He proposed that arsenic methylation involves a chain of oxidation and reduction steps. In several studies, researchers extensively explored the mechanism of arsenic methylation and concluded that the enzymes play crucial role in arsenic methylation.

\section{TOXICITY}

Research have documented arsenic toxicity in humans and animals. Arsenic is a potent carcinogen, leading to skin, bladder, liver, and lung cancers. Arsenic induces epidemiological toxicity. It results in the formation of excess ROS thereby damaging organisms . Arsenic is also known to cause cytotoxicity and genotoxicity. In addition, it is wellestablished fact that chronic exposure to arsenic can lead to arsenicosis, including skin lesions, blackfoot disease, peripheral vascular disease, and cancers. However, several studies have reported arsenicosis due to elevated level.

\section{ASSESSMENT OF TECHNOLOGICAL SOLUTIONS}

Selection of appropriate method to supply water with reduced content relies on several factors and is complicated as the majority of the affected population lives in rural areas deprived off infrastructure and with decentralized water supplies from millions of shallow tube wells (STW) extracting water from shallow aquifers. Mitigation strategies for contamination problem in groundwater therefore should address both technological and the socioeconomic considerations . The various available options suited for getting drinking water with low content can be divided into two categories which include

(i) $J$ Finding an alternative free water source,

(ii) cie Removal from the existing water source

\section{DEEP GROUNDWATER}

The Bihar and the Mekong deltas insinuate that Asrich water occurs mainly in the shallow groundwater, whereas groundwater from deeper aquifers is almost completely free. For example, the study by revealed that only $5 \%$ of the deep tube well $(>150 \mathrm{~m}$ deep) waters had As concentrations above $10 \mathrm{ppb}$ and $1 \%$ exceeded the $50 \mathrm{ppb}$; thus, water supply relying on manually operated deep tube wells could be an appropriate source. However, the depth to As-free aquifers differs between the locations. For example, in the Bengal delta, generally water extraction below $150 / 200 \mathrm{~m}$ deep is considered as deep aquifer, but in many cases this can be below $200 \mathrm{~m}$. As concentration is low at depths at only $>50 \mathrm{~m}$ and $>70 \mathrm{~m}$. The major restriction to the deep water extraction option is its costly installation, leading to its applicability only on community basis. Some other drawbacks to this option include availability of the free deep aquifer, the uncertainty of the groundwater recharge mechanism, the risk of salt water intrusion in coastal areas, and very high concentrations of dissolved Fe and Mn. Mn and Fe cause obnoxious taste and stains in water and laundry even at quite low concentrations exceeding 
$100 \mathrm{ppb}$. The permissible limit of Mn for same human health in groundwater for $\mathrm{Mn}$ is $400 \mathrm{ppb}$.

\section{DUG WELL}

By constructing open wells, generally called dug wells (DWs) with large diameters, As free safe drinking water can be obtained from As contaminated shallow aquifers. DWs used to be one of the alternative sources of water supply in the Ganga delta, before the installation of tube wells. Studies have shown that the As level in most of the DWs is very low due to prevailing oxidative environment and precipitation of $\mathrm{Fe}$ or due to groundwater recharge of the DWs with rainwater with few exceptions. The evaluation of dug well performance in early stages of implementation establishes that these options are appropriate, although prolonged studies report that tube wells will be the preferred choice over DWs.

The reasons for the unpopularity of the DWs are obnoxious smell and taste, turbidity, and distance and time bound limitations to fetch water. Bacteriological contamination is the principal problem associated with the use of DWs water. The use of drinking water from these sources without appropriate treatment may lead to diseases like diarrhea, dysentery, typhoid, cholera, and hepatitis. The frequency of microbial contamination of DWs with thermos tolerant coliforms (TTC) has been found as high as $94 \%$ with seasonal variation with higher contamination during the monsoon compared to the dry season. New DWs usually have high bacterial contamination, which can be regulated by initial or even repeated disinfection like chlorination.

(A) Surface Water. Ponds, lakes, and rivers are generally low or free and can be reintroduced in affected areas as a source of safe drinking water. Most of the affected areas are in the vicinity of a large river and these rivers can serve as sustainable mitigation option for long run, that is, over decades. Similar to the DWs, the major and critical limitation of using ponds and lakes is the risk of potential bacteriological contamination which was also the main reason behind replacement of surface water with groundwater as the drinking water source. Reintroduction of surface water as a source of safe drinking water would require antimicrobial treatment like incorporation disinfectants, use of pond sand filters (PSF), or combined surface water treatment units. About 95\% PSFs have been foundmicrobially contaminated with elevated levels of TTC in the monsoon season as compared to the dry season.

(B) Rainwater Harvesting. Since ancient times, the rainwater harvesting (RWH) has been widely used practice throughout the world as a potential method of utilizing rainwater for domestic water supply. RWH is widely used method at household level globally and there is also an increasing trend on its application at larger community level. The rainwater is safe if it is hygienically maintained and this technology is feasible in areas with average rainfall of $1600 \mathrm{~mm} /$ year or more. In coastal areas, rainwater is the main source of drinking water because of the high salinity in shallow and deep tube wells. In these areas, rainwater is preserved in large ponds, and the experience from such areas can be transferred to other As affected areas. One of the critical limitations of grass root implementation of rain water harvesting technology is its high installation cost in the form of special roofs and large storage tanks for collection and storage of rain water due to the unequal distribution of rainwater over the year. Microbial contamination is also another limitation.which can be avoided by discarding the rainwater collected from first flush . Immense care should also be taken on the materials that come in contact with rainwater (especially zinc and lead), as rainwater is slightly acidic and can result in dissolution of metals and other impurities from materials of the catchment and storage tank, leading to unacceptably high concentrations of contaminants in the water

\section{REMOVAL OF ARSENIC}

Removal of Arsenic mainly depends on the composition and chemistry of the Arseniccontaminated water. Arsenic occurs Arsenitein most of the major reported cases and oxidation of Arsenite toArsenate is considered as necessary to obtain satisfactory As removals.

\section{ARSENIC REMOVAL BY ADSORPTION}

A wide spectrum of different materials have been explored for adsorption of arsenic from groundwater water but iron oxides and oxyhydroxides are the most widely studied and their commercial products already dominate a major portion of the market. In water treatment plants, iron oxyhydroxidesare used as mechanically resistant particles in fixed-bed pressure columns. The application of iron oxyhydroxides is encouraged due to their cheap and easy production. The amorphous structure of such hydroxides provides 
high specific surface area values and their strong affinity and relative high selectivity for the most frequently occurring arsenate species under natural $\mathrm{pH}$-values of potable water.

Tresintsi et al., 2012, synthesized various iron oxyhydroxides between the $\mathrm{pH}$ range 3-12 using the most common low cost iron salts $(\mathrm{FeSO} 4 \cdot \mathrm{H} 2 \mathrm{O}$ and $\mathrm{FeCl} 2 \cdot \mathrm{H} 2 \mathrm{O})$ in a continuous flow kilogram-scale production reactor under intense oxidative conditions to serve as arsenic adsorbents. Synthesized iron oxyhydroxides at acidic ( $\mathrm{pH} 4.0$ ) and highly oxidizing conditions resulted in a very effective arsenic adsorbent comprising of uncrystallizedschwertmannite. The high sorption capacity of hydroxides was mainly determined by the reaction parameters controlling the effective surface charge and the positive role of adsorbed sulfates in the ion exchange with arsenate oxyanions.

The optimized adsorbent demonstrates the highest reported adsorption capacity while keeping the residual arsenic level below $10 \mathrm{mg} / \mathrm{L}$ (Q10-value) and maintaining its superiority in column investigations as compared to commercial granular materials. This method is simple and economically viable-synthetic method adapted in a continuous flow production and a promising technology for scaling up. Zhang and Sun, 2013, invented multifunctional micro/nanostructured $\mathrm{MnO} 2$ spheres successfully and applied them in the removal process of As species from groundwater. Batch experiments revealed that species can be effectively oxidized by the synthesized $\mathrm{MnO} 2$ followed by the adsorption of species. Experimental results of this study insinuated that the synthesized material is repudiated with good adsorption and oxidative capacity required for the removal of arsenic species under controlled conditions. In addition, the synthesized $\mathrm{MnO} 2$ spheres can be efficiently recovered for their reuse by a microfiltration process with limited membrane pore blocking owing to the microstructure of the material. Synthesized $\mathrm{MnO} 2$ spheres are multifunctional materials with good oxidation, adsorption, and separation properties and can be utilized for water purification. Cui et al., 2013, synthesized highly porous, nanostructured $\mathrm{ZrO} 2$ spheres from amorphous $\mathrm{ZrO} 2$ nanoparticles with the help of a food-safe additive, agar powder, which yielded a simple, cheaper, and safer process for the synthesis of $\mathrm{ZrO} 2$ spheres. These $\mathrm{ZrO} 2$ spheres displayed good adsorption capacity on both and at near neutral $\mathrm{pH}$, without the requirement of preoxidation and/or $\mathrm{pH}$ adjustment of the arsenic contaminated water. These $\mathrm{ZrO} 2$ spheres are highly stable, nontoxic, acid-alkali resistant and with high arsenic adsorption capacity. These $\mathrm{ZrO} 2$ nanoparticles seem to be prospecting material for their promising application in removal of arsenic from groundwater.

\section{CONCLUSION}

Arsenic contamination of groundwater is an alarming problem on a global scale. In several parts of the world, biogeochemical processes have resulted in dissolution of naturally occurring into groundwater. In present review, we tried to elaborate on different natural and anthropogenic sources of Arsenic in groundwater including its speciation and mobilization pattern in groundwater. We have also reviewed problem of Arsenic contamination in groundwater in different parts of the world followed by detailed outlook in epidemiology and toxicity mechanisms of Arsenic in animals and humans. In order to combat arsenic problem, various remediation methods based on conventional, modern, and hybrid technologies for removal of Arsenic in several parts of the world have been critically reviewed. The merits and demerits of these technologies have been discussed in detail. Most of the existing technologies for removal of Arsenic involve the direct removal of or converting to followed by removal of. The implementation of mitigation options can be facilitated by setting proper guidelines and to control implementation at appropriate intervals. The awareness of the population is deemed equally important in maintaining and choosing mitigation. However, even for well-aware population, the dilemma is often the ability to meet prohibitive costs versus the wish to improve their situation. For communities public participation encounters the same constraints. Governmental and donor financial and logistic assistance may be essential to reduce arsenicosis. Besides, extensive research should address the understanding of the occurrence, origin, and distribution pattern of arsenic. The government should monitor industrial and agricultural activities leading to Arsenic pollution. More technical assistance should be rendered to mining or chemical plants to deal with sewage and sludge storage and waste treatment.

\section{REFERENCES}

1. Rai, P. Tripathi, S. Dwivedi et al., "Arsenic tolerances in rice (Oryzasativa) have a predominant role in transcriptional regulation of a set of genes including sulphur assimilation 
pathway and antioxidant system," Chemosphere, vol. 82, no. 7, pp. 986-995, 2011.

2. J. Brinkel, M. H. Khan, and A. Kraemer, "A systematic review of arsenic exposure and its social and mental health effects with special reference to Bangladesh," International Journal of Environmental Research and Public Health, vol. 6, no. 5, pp. 1609-1619, 2009.

3. J. L. Stroud, G. J. Norton, M. R. Islam et al., "The dynamics of arsenic in four paddy fields in the Bengal delta," Environmental Pollution, vol. 159, no. 4, pp. 947-953, 2011

4. S. Fendorf, H. A. Michael, and A. van Geen, "Spatial and temporal variations of groundwater arsenic in South and Southeast Asia," Science, vol. 328, no. 5982, pp. 1123-1127, 2010.

5. SantanKumar, Prabhash Kumar, SurabhiRanjan, 'Ground and Surface water Polluted in Manpur Block” IJTSRD ,issn 2456-6470, vol-2, issue2,jan-feb 2018, page- 673-677.

6. N. Mirlean, P. Baisch, and D. Diniz, "Arsenic in groundwater of the Paraiba do Sul delta, Brazil: an atmospheric source?" Science of the Total Environment, vol. 482-483, pp. 148-156, 2014.

7. Mukherjee, M. K. Sengupta, M. A. Hossain et al., "Arsenic contamination in groundwater: a global perspective with emphasis on the Asian scenario," Journal of Health, Population and Nutrition, vol. 24, no. 2, pp. 142-163, 2006.

8. D. Chakraborti, M. M. Rahman, B. Das et al., "Status of groundwater arsenic contamination in Bangladesh: a 14-year study report," Water Research, vol. 44, no. 19, pp. 5789-5802, 2010.
11. J. Nriagu, P. Bhattacharya, A. Mukherjee, J. Bundschuh, R. Zevenhoven, and R. Loeppert, "Arsenic in soil and groundwater: an overview," in Arsenic in Soil and Groundwater Environment, P. Bhattacharya, A. Mukherjee, J. Bundschuh, R. Zevenhoven, and R. Loeppert, Eds., pp. 3-60, Elsevier, Amsterdam, The Netherlands, 2007.

12. M. A. Khan and Y.-S. Ho, "Arsenic in drinking water: a review on toxicological effects, mechanism of accumulation and remediation," Asian Journal of Chemistry, vol. 23, no. 5, pp. 1889-1901, 2011.

13. J. J. Gómez, J. Lillo, and B. Sahún, "Naturally occurring arsenic in groundwater and identification of the geochemical sources in the Duero Cenozoic Basin, Spain," Environmental Geology, vol. 50, no. 8, pp. 1151-1170, 2006.

14. W. G. Cutler, R. C. Brewer, A. El-Kadi et al., "Bioaccessible arsenic in soils of former sugar cane plantations, Island of Hawaii," Science of the Total Environment, vol. 442, pp. 177-188, 2013.

15. R. Tuli, D. Chakrabarty, P. K. Trivedi, and R. D. Tripathi, flc "Recent advances in arsenic accumulation and metabolism in rice," Molecular Breeding, vol. 26, no. 2, pp. 307-323, 2010.

16. Y. Chen, F. Parvez, M. Gamble et al., "Arsenic exposure at low-to-moderate levels and skin lesions, arsenic metabolism, neurological functions, and biomarkers for respiratory and cardiovascular diseases: review of recent findings from the Health Effects of Arsenic Longitudinal Study (HEALS) in Bangladesh," Toxicology and Applied Pharmacology, vol. 239, no. 2, pp. 184 192, 2009.

9. D. P. Shukla, C. S. Dubey, N. P. Singh, M. Tajbakhsh, and M. Chaudhry, "Sources and controls of Arsenic contamination in groundwater of Rajnandgaon and Kanker District, Chattisgarh Central India," Journal of Hydrology, vol. 395, no. 1-2, pp. 49-66, 2010.

10. S. Sthiannopkao, K. W. Kim, S. Sotham, and S. Choup, "Arsenic and manganese in tube well waters of Prey Veng and Kandal Provinces, Cambodia," Applied Geochemistry, vol. 23, no. 5, pp. 1086-1093, 2008. 